Editorial

\title{
El papel de la cirugía en el linfoma gástrico
}

El linfoma gástrico es la presentación extranodal más frecuente de los linfomas malignos y ocurre del 2 al $11 \%$ del total de las neoplasias gástricas.

La sintomatología es muy parecida a la de un síndrome péptico o de una cáncer gástrico, por lo que en pacientes mayores de 40 años, con manifestaciones clínicas de dolor epigástrico, síntomas de reflujo, perdida de peso, se debe proceder a un estudio endoscópico, con el fin de establecer un diagnóstico preciso.

Durante años había diferencias en la definición de linfoma gástrico primario, ya que se aceptaba que si la sintomatología era relacionada a el estómago, era un linfoma gástrico primario, aunque en el estadiaje, se encontrada en fase más avanzada. Por tal motivo, los resultados de tratamiento eran muy difíciles de evaluar, ya que un linfoma tratado con cirugía, pero que era estadio IV, el pronóstico era malo por si mismo y no porque fallará la cirugía. En 1994, en una reunión de trabajo se definieron los estadios, considerándose como primario solo los que involucraban el estómago (IE) o aquellos con afección de los ganglios perigástricos (IIE1) ${ }^{1}$.

En la actualidad se puede establecer que existen dos grupos de linfoma gástrico primario: los difuso B de células grandes y los de mucosa asociada a tejido linfoide (MALT).

Inicialmente la cirugía gástrica, ya fuera resección parcial o total, era considerada como el tratamiento de elección de un linfoma gástrico, ya que se consideraba que por la presentación clínica limitada esta podría ser curativa. Sin embargo, con el seguimiento a largo plazo se observó que $>60 \%$ de los pacientes tenían recurrencia, así como complicaciones tardías relacionadas con la cirugía.

\section{¿Cuales son las indicaciones de la cirugía en el linfoma gástrico?}

Diagnóstico: hace más de 35 años, la única forma de hacer un diagnóstico era por medio de cirugía. En la actualidad con la introducción de la endoscopia, sobre todo de la endoscopia con ultrasonido ésta ya no es una indicación, ya que la biopsia obtenida por endoscopia da un $97 \%$ de confianza en el diagnóstico. Para tal fin se recomienda un mínimo de 6 biopsias del sitio aparentemente afectado, así como otras 6 de sitios no afectados. En dos estudios recientes sobre este tema, en el 100\% de los pacientes el diagnóstico se estableció con el endoscopio. En pacientes con MALT gástrico con una predilección por la submucosa, se recomienda hacer más biopsias fuera del sitio clínicamente afectado, con el fin de poder definir el tratamiento de manera más adecua$\mathrm{da}^{2,3}$. Por tal motivo la cirugía ya no se requiere para el diagnóstico ${ }^{4}$.

Estadificación: la definición de la extensión de la enfermedad en pacientes con linfoma es esencial, por tal motivo se consideró que solo por medio de una laparotomía exploradora se podía establecer una extensión correcta. Con la introducción de métodos no invasivos como la tomografía computada, y la tomografía por emisión de positrones, han hecho que la cirugía ya no sea necesaria.

Evitar complicaciones: se consideraba que el administrar radioterapia o quimioterapia a un paciente con un linfoma gástrico podía tener complicaciones como sangrado o perforación, algunas de las cuales podrían ser letales. En varios estudios tanto retrospectivos como prospectivos (con más de 2000 pacientes incluidos) sólo hubo 5 casos de sangrado y 3 perforaciones $(<1 \%)$, y dado que en esos casos se tiene una vigilancia estrecha, ninguno fue fatal. Por lo mismo la cirugía no parece tener un papel en este tipo de indicaciones. 


\section{A. Avilés}

Tratamiento: ya se mencionó que se consideraba que si el linfoma gástrico tenía una presentación tan limitada, la cirugía podía ser curativa. Tomando en consideración la tasa alta de recurrencias, se añadía radioterapia o quimioterapia, pero después de la cirugía, y en esos casos se contaba como éxito, pero sin definir cuál de los tratamientos era el factor de éxito. Desde 1989, se han llevado a cabo múltiples estudios tanto retrospectivos como dos prospectivos, analizando las diversas opciones terapéuticas: cirugía, cirugía más radioterapia, cirugía más quimioterapia o bien quimioterapia sola. En 5 de esos estudios se comprobó la alta tasa de recurrencia y una menor supervivencia a 5 años con la cirugía sola y la cirugía con radioterapia. No hubo diferencias significativas con la cirugía y quimioterapia y la quimioterapia sola; pero con el uso de cirugía la presencia de complicaciones tardías relacionadas con el acto quirúrgico eran altas y en ocasiones graves. Por tal motivo se considera que la cirugía no tiene un papel importante como parte del tratamiento en esta neoplasia ${ }^{2,3,8}$.

En conclusión la cirugía en el linfoma gástrico debe quedar limitada a casos muy especiales, en los cuales el uso de radioterapia o quimioterapia tengan contraindicaciones formales; pero en el momento actual la cirugía no tiene ningún papel específico en el tratamiento del linfoma gástrico primario.

Dr. Agustin Avilés

Editor Asociado Revista Oncología

Investigador Titular D

Unidad de Investigación en Enfermedades Oncológicas Hospital de Oncología Centro Médico Nacional, IMSS

México, D.F. México agustin.aviles@imss.gob.mx.4

\section{Referencias}

1. Rohatainer A, d'Amore F, Coiffier B et al. Report of a workshop to discuss the pathological and staging clasification og gastrointestinal tract lymphoma. Ann Oncol 1994;5:397-400.

2. Avilés A, Nambo MJ, Neri N, et al. The role of surgery in primary gastric lymphoma. Ann Surg 2004; 240:44-50.

3. Avilés A, Nambo MJ, Neri N, et al. Mucossa associated lymphoid tissue (MALT) lymphoma of the stomach. Med Oncol 2005; 22:57-63.

4. Yoo SS, Cuit DG, Portlock CS, Karpeh MS. The diminished role of surgery in the treatment of gastric lymphoma. Ann Surg 2004;240:28-37.

5. Montalban C, Castrillo JM, Abraira V, et al. Gastric B-cell mucossa associated lymphoid tissue (MALT) lymphoma. Ann Oncol 1995;6:355-362.

6. Binn M, Ruskone-Fourmestraux A, et al. Surgical resection plus chemotherapy versus chemotherapy alone in gastric lymphoma. Ann Oncol $2003 ; 14: 1751-1757$.

7. Gobbi PG, Ghirardelli ML, Cavalli C, et al. The role of surgery in the treatment of gastrointestinal lymphoma other than low-grade MALT lymphoma. Haematologica 2000;85:454-457.

8. Koch P, Probst A, Berdel WE, et al. Treatment results in localized primary gastric lymphoma. J Clin Oncol 2005; 23:7050-7059. 